University of Nebraska - Lincoln

DigitalCommons@University of Nebraska - Lincoln

Faculty Publications from the Harold W. Manter Laboratory of Parasitology

6-1950

\title{
A New Species of the Acanthocephalan Genus Arhythmorhynchus from Sandpipers of Alaska
}

\author{
Harley J. Van Cleave \\ Robert L. Rausch \\ University of Washington, rausch@uw.edu
}

Follow this and additional works at: https://digitalcommons.unl.edu/parasitologyfacpubs

Part of the Parasitology Commons

Van Cleave, Harley J. and Rausch, Robert L., "A New Species of the Acanthocephalan Genus Arhythmorhynchus from Sandpipers of Alaska" (1950). Faculty Publications from the Harold W. Manter Laboratory of Parasitology. 385.

https://digitalcommons.unl.edu/parasitologyfacpubs/385

This Article is brought to you for free and open access by the Parasitology, Harold W. Manter Laboratory of at DigitalCommons@University of Nebraska - Lincoln. It has been accepted for inclusion in Faculty Publications from the Harold W. Manter Laboratory of Parasitology by an authorized administrator of DigitalCommons@University of Nebraska - Lincoln. 


\title{
A NEW SPECIES OF THE ACANTHOCEPHALAN GENUS ARHYTHMORHYNCHUS FROM SANDPIPERS OF ALASKA
}

\author{
Harley J. Van Cleave \\ Department of Zoology, University of Illinois, Urbana, Illinois \\ Robert L. RAUSCH \\ United States Public Health Service, Anchorage, Alaska
}

In the spring of 1949, a survey of the parasites of birds of Alaska, especially in the vicinity of Juneau, was conducted by Robert L. Rausch and Ralph B. Williams. Among the Acanthocephala encountered there were specimens of the genus Arhythmorhynchus in two species of sandpipers, Erolia ptilocnemis couesi (Ridgway) (the Aleutian sandpiper) and Erolia alpina pacifica (Vieillot) (the red-backed sandpiper). This parasite was present in such numbers as to make morphological and taxonomic study profitable. The species is clearly distinct from all other members of the genus and is here described as Arhythmorhynchus comptus n. sp.

On the first day of collecting (March 3, 1949), three specimens of Erolia ptilocnemis couesi were taken from a large flock. Two of these individuals were heavily infected with $A$. comptus. On the following day, 41 birds were taken from apparently the same flock in connection with various studies in progress. These included 15 of the Aleutian sandpiper and 26 of the red-backed sandpiper. In the 15 individuals of Erolia ptilocnemis couesi (the Aleutian sandpiper), 167 worms were found in the 11 infected individuals, with an average of slightly more than 15 worms per infected bird and a minimum of 3 and maximum of 42 worms per bird. Of E. alpina pacifica (the red-backed sandpiper), 25 of the 26 birds examined were infected with a total of 204 worms, making an average of only slightly more than 8 worms per infected bird, with individual infections ranging from 1 to 20 worms. The parasites were scattered through the lower half of the small intestine without being restricted to any localized portion of it. In both species of host, some other intestinal worms. chiefly cestodes, were encountered but in small numbers. Even the heavily infected birds were fat and neither the weight nor the general appearance gave evidence that the parasites affected the condition of the host.

Subsequently, other land, shore and water birds of the vicinity were examined in the hopes of locating additional vertebrate hosts for A. comptus. Although several other species of ACANTHOCEPHala were found, only one additional host species and an extension of the seasonal occurrence in this and a previously recognized definitive host have been added to the records mentioned above. On October 29, 1949, R. B. Williams examined a specimen of the surf-bird, Aphriza virgata (Gmelin), from the Lynn Canal near the mouth of Eagle river, approximately 30 miles north of Juneau. Two immature specimens of Arhythmorhynchus comptus were recovered from the intestine of the surf-bird and from the same vicinity a single large but immature specimen of the same parasite was found in each of two individuals of the Aleutian sandpiper. These constitute the only available records of the occurrence of $A$. comptus in extension of the records upon which the description of the species is based.

Received for publication, January 17, 1950. 
S. Yamuguti (1939: 333) described as Polymorphus eroliae an acanthocephalan which he discovered in Erolia alpina sakhalina (Vieillot) of Sizuoka Prefecture, Japan. Both the illustrations and the description which he gave indicate that the generic assignment was in error, since the features of this species are clearly those of the genus Arhythmorhynchus. Consequently, Polymorphus eorliae Yamaguti, 1939 becomes Arhythmorhynchus eroliae (Yamaguti, 1939). This species has many points of morphology in common with Arhythmorhynchus comptus. However, the two species are clearly distinguishable one from the other on the basis of size of the proboscis and number of proboscis hooks.

Taxonomically related birds of the European continent carry a wide representation of acanthocephalan parasites, but in no instance is there any species recorded which even remotely resembles Arhythmorhynchus comptus. A. frassoni, A. invaginabilis, $A$. macrourus, and $A$. longicollis are the only representatives of the genus recorded from northern and central European birds. All but the last one of these have such distinctively different formula of proboscis armature that they could not possibly be confused with $A$. comptus. $A$. longirostris is very imperfectly known. Both Baylis (1922:426) and Meyer (1931: 14 and 1932:45) record the species without giving any information on the number and arrangement of the proboscis hooks although both refer to the proboscis as cylindrical or nearly so. On this feature, $A$. comptus is markedly different from $A$. longicollis.

Some light is thrown upon the rather sharp geographical limitations and host relations of $A$. comptus by examination of negative records for birds closely related taxonomically or ecologically to the normal hosts (Table 1). Eleven of 14 species of sandpipers and taxonomically related birds (a total of 41 individuals), collected in Alaska, were all negative for $A$. comptus and specimens of one of its normal hosts, the red-backed sandpiper, from different flocks and localities were likewise negative. Furthermore, previously unpublished observations (Table 1) on the parasites of 169 additional specimens representing 21 species of sandpipers, plovers and related species, from various localities in Canada and the United States were likewise all negative for $A$. comptus. Ordinarily, negative records have relatively little significance, but when they are limited to potential hosts of similar habits, and of fairly uniform taxonomic relationship, they serve as a means of delimiting the geographical and seasonal distribution and host relations of a parasite.

Field collections, by Rausch supplemented by materials collected by Williams, include such a comprehensive sampling of related birds on the North American continent that the results are incorporated as Table 1.

The parasites were killed in Alcohol-Formol-Acetic (A.F.A.) mixture and were shipped immediately to Urbana by air mail in this fluid. Upon arrival they were transferred to alcohol. In life and following preservation, the specimens were of bright orange color. Attempts to bleach with chlorine and other routine bleaching procedures were unsuccessful but when the specimens were brought into $95 \%$ alcohol the color leached out completely. An unbleached specimen and the supernatant alcohol were treated with concentrated sulphuric acid, whereupon they turned a greenish blue indicating that the color was probably due to the presence of carotene. In this connection, it is interesting to note that most if not all of the species of ACANTHOCEPHALA which are yellow or orange in life, are found in the intestine of vertebrates which feed upon arthropods. 


\section{TABLE 1.}

Records of the examination of North American sandpipers, plovers, and related birds for Acanthocephala of the genus Arhythmorhynchus. *, indicates A. comptus found; -, birds examined but no $A$. comptus; 0 , no birds of this species examined from the locality

The species are arranged in the sequence of the A. O. U. Check-list, prepared with the cooperation of Dr. Harvey I. Fisher.

\begin{tabular}{|c|c|c|}
\hline & Alaska & $\begin{array}{l}\text { United States } \\
\text { and/or Canada }\end{array}$ \\
\hline Ereunetes pusillus semipalmated sandpiper $\ldots \ldots \ldots \ldots \ldots \ldots \ldots$ & - & - \\
\hline 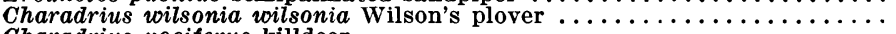 & 0 & - \\
\hline Charadrius vociferus killdeer $\ldots \ldots \ldots \ldots \ldots \ldots \ldots \ldots \ldots \ldots \ldots \ldots \ldots \ldots$ & 0 & - \\
\hline Charadrius hiaticulata semipalmatus semipalmated plover . . . . . . . . & - & - \\
\hline 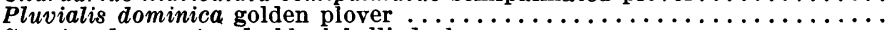 & - & - \\
\hline Squatarola squatarola black-bellied plover . . . . . . . . . . . . . & - & 0 \\
\hline 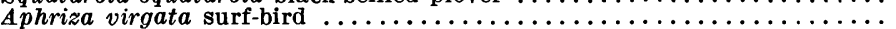 & * & 0 \\
\hline 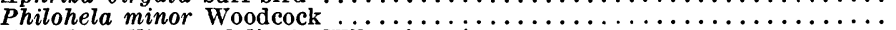 & 0 & - \\
\hline Capella gallinago delicata wilson's snipe ................. & 0 & - \\
\hline 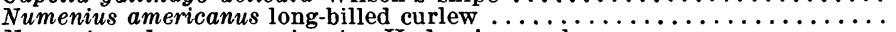 & 0 & - \\
\hline 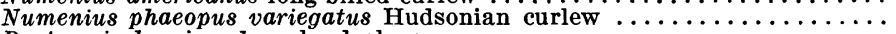 & - & 0 \\
\hline 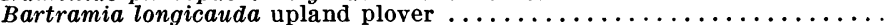 & 0 & - \\
\hline 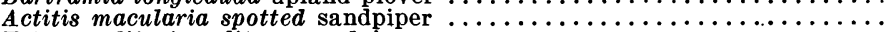 & 0 & - \\
\hline 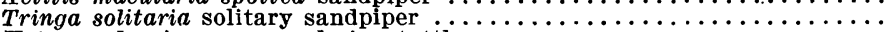 & 0 & - \\
\hline 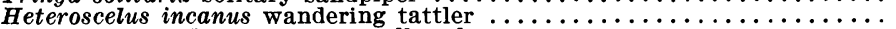 & - & 0 \\
\hline 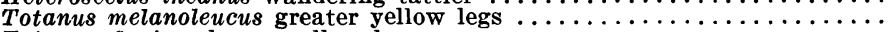 & 0 & - \\
\hline 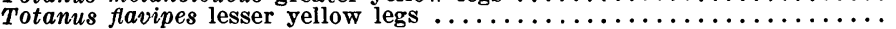 & 0 & - \\
\hline 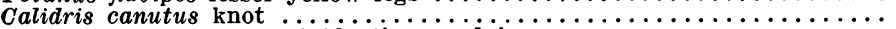 & 0 & - \\
\hline 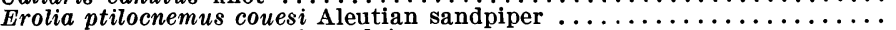 & * & 0 \\
\hline 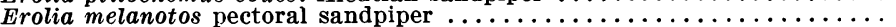 & - & - \\
\hline Erolia bairdii Baird's sandpiper $\ldots \ldots \ldots \ldots \ldots \ldots \ldots \ldots \ldots \ldots \ldots \ldots \ldots \ldots$ & - & - \\
\hline 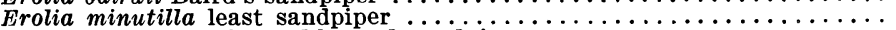 & - & - \\
\hline Erolia alpina pacifica red-backed sandpiper $\ldots \ldots \ldots \ldots \ldots \ldots \ldots \ldots \ldots \ldots \ldots \ldots \ldots \ldots$ & * & - \\
\hline 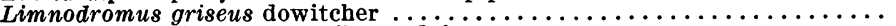 & - & - \\
\hline Micropalama himantopus stilt sandpiper $\ldots \ldots \ldots \ldots \ldots \ldots \ldots \ldots \ldots \ldots \ldots \ldots \ldots \ldots \ldots \ldots$ & - & - \\
\hline 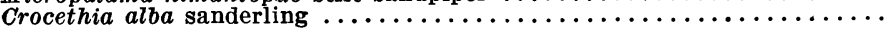 & 0 & - \\
\hline
\end{tabular}

\section{Arhythmorhynchus comptus n. sp.}

(Figs. 1-6)

Description. With the characteristics of the genus Arhythmorhynchus. Body (Fig. 3) very long and narrow with a slight inflation near the anterior end. Proboscis short, spindle-shaped. Neck (N) relatively long. Females 40 to $55 \mathrm{~mm}$ in length with a maximum diameter of from 0.8 to $1 \mathrm{~mm}$; proboscis 0.43 to $0.48 \mathrm{~mm}$ long by 0.25 to 0.40 in width at near middle; neck 0.46 to $0.80 \mathrm{~mm}$ long. Proboscis (Fig. 1) armed with 15 or 16 longitudinal rows of 8 or 9 hooks each, those near middle of proboscis usually 0.044 to $0.048 \mathrm{~mm}$ long, relatively heavy but frequently with poorly defined roots. Embryos (Fig. 6) within body cavity of females 0.093 to $0.101 \mathrm{~mm}$ long by 0.022 to $0.026 \mathrm{~mm}$ wide, with a short, rounded polar prolongation at each end.

Males: (Fig. 3) 23 to $32 \mathrm{~mm}$ long with maximum diameter of 0.635 to $0.807 \mathrm{~mm}$; proboscis (Fig. 2) slightly smaller than in female, 0.32 to $0.44 \mathrm{~mm}$ long by 0.17 to $0.24 \mathrm{~mm}$ in maximum width; neck 0.35 to $0.75 \mathrm{~mm}$ long. Proboscis armature as in female, except that more of the hooks are about $0.044 \mathrm{~mm}$ in length. Two testes (TA, TP) contiguous, each about 1 to $1.5 \mathrm{~mm}$ long, located in anterior part of body about 2 or $3 \mathrm{~mm}$ behind the inflated, spine covered area (S). Cement glands (C) apparently only two, extremely long and tubular, from 13 to $24 \mathrm{~mm}$ in length.

Neck and anterior region of trunk of both sexes covered with a thick, hyaline cuticula. Fore part of trunk (Fig. 3a) somewhat inflated (I) for a distance of about $2.5 \mathrm{~mm}$, often with a slight secondary constriction at about the anterior third. A relatively short spine field 1 to $2.5 \mathrm{~mm}$ in length (S) encircles the anterior extremity of the trunk with the anterior spines closely set but progressively more widely dispersed posteriorly. Roots of the body spines more conspicuous in stained mounts than the spines, the latter usually about $0.015 \mathrm{~mm}$ long with roots irregularly circular in outline, about 0.015 to $0.020 \mathrm{~mm}$ in diameter.

The subcuticular nuclei of the trunk are restricted to a zone in the inflated region of the trunk and are wholly lacking both posterior and anterior to this region. In mature individuals, these nuclei of the subcuticula (Fig. 5, N F) are highly fragmented, rounded bodies from 0.010 to $0.025 \mathrm{~mm}$ in diameter, packed so closely that the diameter of each fragment is usually less than the distance between the fragments. The nucleated zone starts at a level near the posterior end of the proboscis receptacle, almost coincident with the posterior limit of the spine field, and extends for a distance of 1.5 to $3 \mathrm{~mm}$, forming an uninterrupted band around the entire circumference of the body. In males of $A$. comptus, the nucleated zone extends back- 
ward somewhat beyond the anterior limit of the anterior testis. Both anteriorly and posteriorly the nuclear fragments become more widely dispersed but in a relatively short distance they disappear completely, leaving most of the vast syncytial subcuticula entirely devoid of nuclei. This restricted localization of the subcuticular nuclei is apparently distinctive of the genus Arhythmorhynchus (Van Cleave, 1916). In some other genera of AcANTHocephala, there is no fixed pattern of localization while the sharpest contrast with conditions found in Arhythmorhynchus is that encountered in the family NEOECHINORHYNCHIDAE. In the last mentioned family, the giant nuclei of the subcuticula are widely dispersed in a longitudinal linear series with all of them restricted to the sagittal plane of the trunk.

The main trunks of the lacunar system are chiefly lateral in position. Most of the females are so filled with developing eggs that details of the genital tract could not be made out. In a young female which had not become gravid (Fig. 4), the vagina (V) and part of the uterus (U) are clearly shown but the uterine bell and the selective apparatus are obscured by other structures. The double-walled receptacle of the proboscis bears the brain near the middle of its extent. The lemnisci (L, Fig. 3a), irregularly tubular in shape, extend about 1.2 to $1.8 \mathrm{~mm}$ posteriorly into the trunk.

Hosts: Erolia ptilocnemis couesi (Ridgway), the Aleutian sandpiper, and Erolia alpina pacifica (Vieillot), the red-backed sandpiper in the vicinity of Juneau, Alaska, on March 3 and 4, 1949. Additional records from the Aleutian sandpiper and the surf-bird, Aphriza virgata (Gmelin), near the mouth of Eagle River, Alaska, October 29, 1949.

Developmental stages: Wholly unknown.

Type material: Holotype male, allotype female and series of paratypes of both sexes in collection of H. J. Van Cleave, Urbana, Illinois and paratypes in collection of Robert L. Rausch, Anchorage, Alaska.

Comparisons: Because of the wide geographical distribution and migratory habits of many of the species of the family ScolopacidaE, to which the sandpipers belong, and likewise because of the similarities in food habits and in ecological relations of water and shore birds, a careful check has been made between $A$. comptus and all other members of this genus. No member of this genus has been reported previously from sandpipers of either Europe or America (Meyer 1932-33).

Arhythmorhynchus eroliae (Yamaguti, 1939) and Polymorphus capellae Yamaguti, 1935, both from Japan, are the only two species of ACANTHOCEPHALA previously reported from sandpipers and related birds which are considered in this report. Both of these species are clearly distinct from $A$. comptus. While the last named species has proboscis armature consisting of 15 or 16 longitudinal rows of 8 or 9 hooks each, $A$. eroliae has 18 longitudinal rows of 12 or 13 hooks each and Polymorphus capellae, of uncertain generic assignment, has 14 to 16 hooks in each of its 17 or 18 longitudinal rows.

A. comptus is clearly distinct from every other known species of the genus, all of which have conspicuously greater numbers of proboscis hooks. This is particularly true of the numbers of hooks in each longitudinal row. In $A$. comptus, there are but 8 or 9 hooks per longitudinal row while the smallest number recorded for any other species of the genus is 13 . Previous studies have shown that individual variability of this magnitude is never found in members of the genus Arhythmorhynchus.

\section{REFERENCES}

BAYlis, H. A. 1922 A new cestode and other parasitic worms from Spitzbergen, with a note on two leeches. Results of the Oxford University Expedition to Spitzbergen, No. 6. Ann. and Mag. Nat. Hist. Ser. 9, 9: 421-427.

Meyer, A. 1931 Die Acanthocephalen des arktischen Gebietes. Fauna Arctica 6: 11-20. 1932-3 Acanthocephala. Bronn's Klassen und Ordnungen des Tierreichs. B. 4 ; Abt. 2, Buch 2. Leipzig.

Van Cleave, H. J. 1916 A revision of the genus Arhythmorhynchus with descriptions of two new species from North American birds. J. Parasit. 2: 167-174. 
YamaguTI, S. 1935 Studies on the helminth fauna of Japan. Part 8. Acanthocephala, I. Jap. J. Zool. 6(2): 247-278.

-1939 Studies on the helminth fauna of Japan. Part 29. Acanthocephala, II. Jap. J. Zool. 8(3): 317-351.

Explanation of Plate

Katharine Hill Paul, scientific artist in the department of Zoology, University of Illinois, prepared the drawings and arranged the plate. All drawings were made with the aid of a camera lucida from stained specimens mounted in clarite.

The scale between Figs. 1 and 2 applies to both of these and likewise to Figs. 4 and 5.

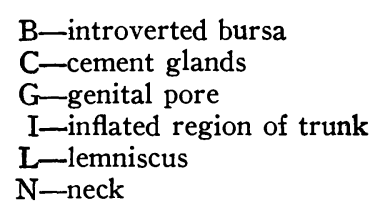

Symbols

Morphology of Arhythmorhynchus comptus n. sp.

FIg. 1. Proboscis, neck and anterior end of trunk of a female.

FIG. 2. Proboscis, neck and anterior end of trunk of a male.

FIG. 3. Entire body of holotype male (A) anterior end, (B) posterior end.

FIg. 4. Posterior extremity of an immature female showing vagina (V) and a portion of the uterus (U).

FIg. 5. Segment of the trunk of a male in the inflated region showing distribution of fragmented nuclei of the subcuticula.

FIg. 6. Eggs from the body cavity of a female. 


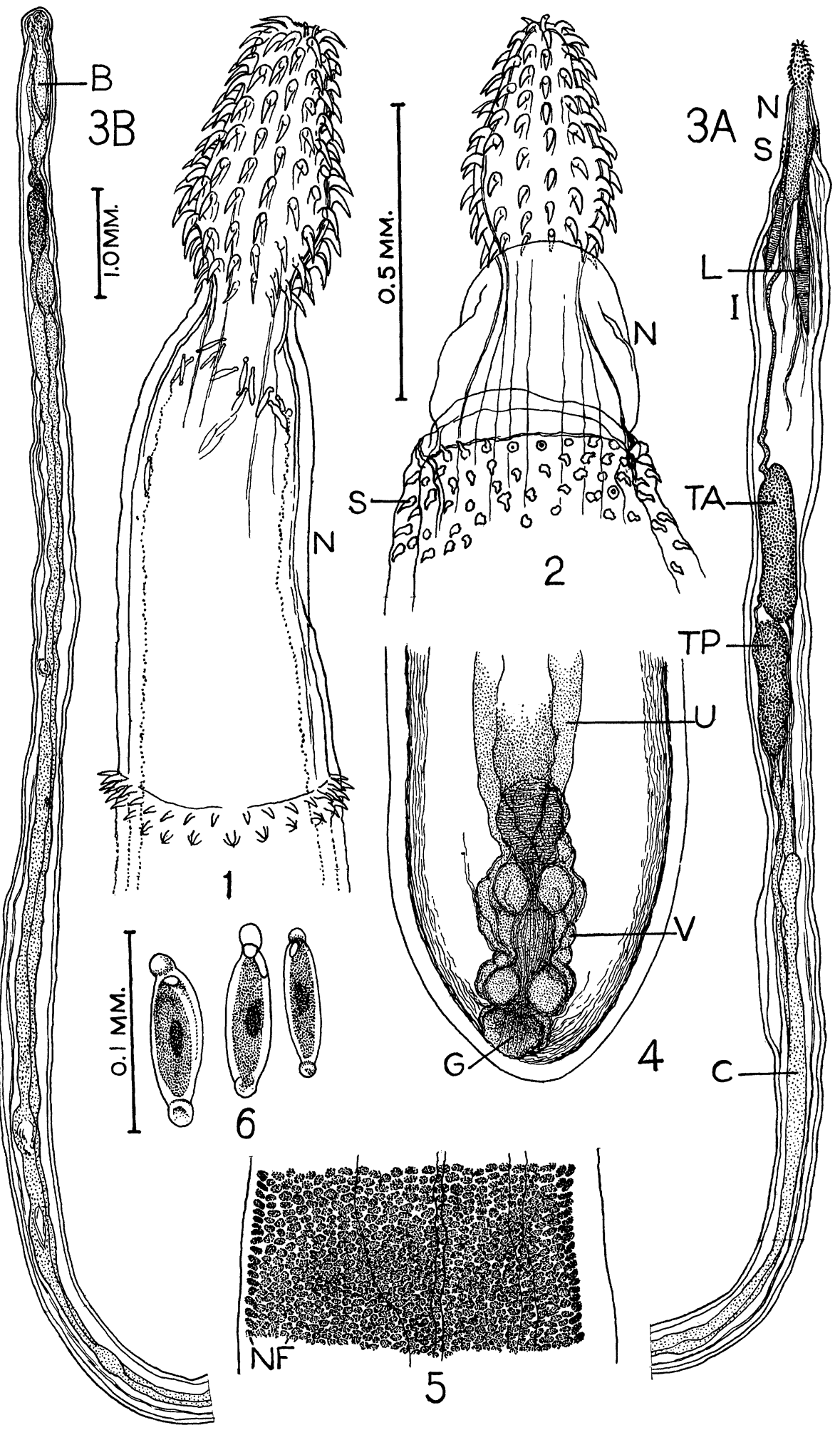

